\title{
Advances in measurement technology and intelligent instruments for manufacturing engineering
}

\author{
Yongsheng Gao • Wei Gao • Yasuhiro Takaya • \\ Michael Krystek
}

Published online: 19 January 2010

(C) Springer-Verlag London Limited 2010

A special issue in the International Journal of Advanced
Manufacturing Technology (http://www.springer.com/
engineering/production+eng/journal/170), ISSN: 0268-3768
(print version), ISSN: 1433-3015 (electronic version), Springer,
London, UK

12 December 2009

The requirements for high precision and high quality components and devices in meeting the needs of modern industry and society in many disciplines such as semiconductors, optics, nanotechnology, MEMS, manufacturing, biomedical, and environmental engineering, make measure-

\footnotetext{
Y. Gao $(\bowtie)$

Department of Mechanical Engineering,

Hong Kong University of Science and Technology,

Clear Water Bay, Kowloon,

Hong Kong SAR, China

e-mail: meygao@ust.hk

W. Gao

Department of Nanomechanics, Tohoku University,

Aramaki Aza Aoba 6-6-01, Aoba-ku,

Sendai 980-8579, Japan

e-mail: gaowei@cc.mech.tohoku.ac.jp

Y. Takaya

Department of Mechanical Engineering,

Graduate School of Engineering, Osaka University,

2-1 Yamadaoka, Suita,

Osaka 565-0871, Japan

e-mail: takaya@mech.eng.osaka-u.ac.jp

M. Krystek

Physikalisch Technische Bundesanstalt,

Bundesallee 100,

38116 Braunschweig, Germany

e-mail: Michael.Krystek@ptb.de
}

ment technology and intelligent instruments, which sense, measure, and report, more important than ever and necessary for the rapid development of information technology.

Papers published in this special issue were selected and updated from those presented at the 8th International Symposium on Measurement Technology and Intelligent Instruments (ISMTII 2007; http://www.ismtii2007.mech. tohoku.ac.jp/) held at Tohoku University, Sendai, Japan, during 24-27 September 2007.

ISMTII 2007 was organized by the International Committee on Measurements and Instrumentation (ICMI; http:// ihome.ust.hk/ meygao/ICMI/), Japan Society for Precision Engineering (JSPE, Technical Committee of Intelligent Measurement with Nanoscale), Korean Society for Precision Engineering (KSPE), Chinese Society for Measurement (CSM), and Tohoku University. The symposium was also supported by Center for Precision Metrology of UNC at Charlotte and Singapore Institute of Manufacturing Technology.

Based on the review and recommendations by the Publication Committee of ISMTII 2007 (http://www. ismtii2007.mech.tohoku.ac.jp/conference_committees.htm), the guest editors selected and organized journal level review of papers by $4-5$ reviewers for each paper. The review has been seen as an extensive process concentrating on originality and quality. While emphasizing the practical techniques to improve precision and efficiency, theoretical examinations of measurement processes and systems were also considered.

The guest editors finally recommended publication of ten updated and/or revised versions of some of the best ISMTII 2007 papers, including one which received Best Papers Award of Poster Presentation (http://ihome.ust.hk/ meygao/ ICMI/ISMTII/2007/ReportISMTII2007v3.pdf), while most of the papers were accepted papers of Invited Sessions at 
ISMTII 2007, in this special issue of International Journal of Advanced Manufacturing Technology (IJAMT; http://www. springer.com/engineering/production+eng/journal/170). This special issue presents recent advances in this important field.

The topics include form profile measurement of micro aspheric surface, optical defect detection of next generation semiconductor wafer, measurement error processing, and design analysis for precision measurement, key devices, and control of these devices for precision measurement and innovative sensing devices for modern industries, in particular, for many manufacturing industries. For these topics, novel designs in sensor and sensing systems and novel techniques are reported. Modeling and investigations on characteristics and performances of precision sensor and sensing systems are also presented.
We believe that this special issue presents the newest applicable information for active researchers and engineers and form a basis for further research in the field of measurement technology and intelligent instruments to create new and practical instrument systems and processes with enhanced functionality, precision, and performance and with reduced cost.

We would like to thank all authors for their contributions to this special issue. In particular, we would like to thank all reviewers of this special issue for their careful reviews of the papers. Finally, we would also like to express our thanks and appreciations to Professor John Davies, Editor-in-Chief of IJAMT, for his kind offer to publish selected ISMTII 2007 papers in IJAMT, and to the publishing staff members of IJAMT for their great work for this special issue. 